\title{
Virulence of coagulase-deficient mutants of Staphylococcus aureus in experimental endocarditis
}

\author{
L. M. BADDOUR, M. M. TAYIDI, E. WALKER* D. McDEVITT† and T. J. FOSTER $\dagger$ \\ Department of Medicine, Section of Infectious Diseases, University of Tennessee Medical Center at Knoxville, \\ Knoxville, Tennessee 37920-6999, " Department of Statistics, University of Tennessee, Knoxville, Tennessee \\ 37996-0532, USA and † Department of Microbiology, Moyne University, Trinity College, Dublin 2, Ireland
}

\begin{abstract}
Summary. A sensitive rat endocarditis model which employed relatively small inocula $\left(\leqslant 10^{4} \mathrm{cfu}\right)$ was used to examine the role of coagulase in the pathogenesis of infection. Rats with indwelling, intracardiac catheters were challenged intravenously with three strains of Staphylococcus aureus. The virulence of a coagulase-positive parental strain DU5808 was compared in terms of its ID50 for resected vegetations and catheters to that of two coagulasenegative mutant strains (DU5809 and DU5814) which had undergone site-specific mutagenesis. Confidence intervals of infection rates were calculated and comparisons were performed of weights of infected vegetations, bacterial concentrations in vegetations and early mortality rates. From these virulence parameters, it was concluded that there were no differences in virulence among the three strains. The results from this investigation support the previous findings in mouse models of subcutaneous infection and mastitis, which indicated that coagulase production by $S$. aureus does not appear to function as a virulence factor. Together, these data refute the longheld belief that coagulase is important in the pathogenesis of infection and indicate that other markers of virulence must be operative in diseases caused by the enduring pathogen $S$. aureus.
\end{abstract}

\section{Introduction}

Staphylococcus aureus is responsible for various clinical syndromes, ${ }^{1}$ including infective endocarditis, osteomyelitis, toxic shock syndrome and soft tissue infections. Results from numerous investigations ${ }^{1-3}$ confirm that this bacterium has a panoply of virulence factors that play a part in the disease process. Staphylococcal coagulase has been considered an important virulence factor; earlier studies ${ }^{4-6}$ demonstrated reduced virulence of coagulase-negative mutants of $S$. aureus isolated after chemical mutagenesis. Selective mutagenesis techniques have been used to recover coagulase-deficient mutant strains of S. aureus for assay in two animal infection models. ${ }^{7}$ In contrast to the results of virulence studies with coagulase-negative $S$. aureus mutant isolates that had been obtained by chemical mutagenesis, studies that included the coagulase-deficient mutants that had undergone site-specific mutagenesis showed that they were as virulent as their respective coagulaseproducing parent strains in mouse models of subcutaneous infection mastitis. However, relatively high inocula $\left(\geqslant 10^{7} \mathrm{cfu}\right)$ were used to establish soft tissue infections.

The question arose as to whether these two mouse infection models were sensitive enough to detect the contribution of a single virulence factor, because relatively large inocula were used to produce disease. The large inocula could have obscured the contribution of a single virulence factor of a well-equipped bacterium like $S$. aureus. Similarly, another investigation demonstrated that microcapsule production by $S$. aureus seemed to attenuate virulence in a rat endocarditis model in which lower inocula $\left(<10^{4} \mathrm{cfu}\right)$ were used to establish infection. No such attenuation of virulence was seen in mouse infection models which required much larger inocula $\left(>10^{6} \mathrm{cfu}\right)$ of the same $S$. aureus strains to produce renal abscesses and death.

In the present study, a more sensitive rat endocarditis model was used to investigate the role of coagulase as a virulence factor for $S$. aureus. A coagulase-positive parent strain was compared to two coagulase-negative mutant strains which had undergone site-specific mutagenesis in ID50 studies. 


\section{Materials and methods}

\section{Bacteria}

The three $S$. aureus strains used in this investigation were recently characterised by Phonimdaeng et al. The coagulase-positive parent strain DU5808 is a phage 85 lysogen of strain NCTC $8325-4$ which does not produce a capsule (J. M. Fournier, personal communication). The coagulase-defective mutants both carried a coa : :EM ${ }^{\mathrm{r}}$ mutation. ${ }^{7}$ Strain DU5809 is a coa mutant of DU5808; DU5814 in addition carries the $h l a:: \mathrm{EM}^{\mathrm{r}}$ and $h l b:: \phi 42 \mathrm{E}$ mutation affecting $\alpha$ - and $\beta$-toxin, respectively. ${ }^{8,9}$

The strains were stored at $-70^{\circ} \mathrm{C}$ in Trypticase Soy Broth (Difco Laboratories) with glycerol (Fisher Scientific, St Louis, USA) $15 \% \mathrm{v} / \mathrm{v}$. Working isolates were maintained at $4^{\circ} \mathrm{C}$ for up to 2 months on Trypticase Soy Agar plates supplemented with sheep blood (BBL Microbiology Systems, Cockeysville, MD, USA) $5 \%$.

Staphylococci were grown overnight at $37^{\circ} \mathrm{C}$ on sheep blood $5 \%$ agar plates and then removed from the agar surface and suspended in sterile phosphatebuffered saline (PBS; 0.005 M phosphate-0.15 M NaCl, $\mathrm{pH} 7 \cdot 24)$. The bacteria were washed once by centrifugation at $1000 \mathrm{~g}$ for $10 \mathrm{~min}$ and resuspended in PBS. The desired inoculum was determined spectrophotometrically at $590 \mathrm{~nm}$ (Junior Model 35; Perkin-Elmer, Norwalk, CT, USA) and was confirmed by quantitative colony counts after diluting the inocula in PBS and plating them on to sheep blood $5 \%$ agar.

\section{Animal endocarditis model}

A catheter-induced rat model of experimental endocarditis ${ }^{10}$ was used to examine the virulence of the three staphylococcal strains. Male Sprague-Dawley rats (Harlan, Sprague-Dawley, Indianapolis, IN, USA) weighing c. $200 \mathrm{~g}$ were anaesthetised with a ketamine-xylazine solution and a polyethylene catheter (Intramedic PE10; Clay-Adams, Parsippany, NJ, USA) was passed down the right common carotid artery into the lumen of the left ventricle. The catheter was tied in place and the neck incision was closed. After $48 \mathrm{~h}$, the rats were placed in a restraining device (DeCapicones, Braintree Scientific, Braintree, MA, USA) and $0.5 \mathrm{ml}$ of the bacterial inoculum was injected through a tail vein via a 24-gauge intravenous catheter (Insyte, Deseret Medical, Sandy, UT, USA) which was then removed. The rats were killed $96 \mathrm{~h}$ later and the anterior rib cage, heart and proximal major vessels were resected. The aorta and left ventricle were opened and the position of the intraventricular tip of the catheter and the presence or absence of vegetations were determined.

Catheters were removed and placed in test tubes with trypticase soy broth for qualitative culture. Vegetations were excised, weighed (wet) and homogenised with a mortar and pestle in $1 \mathrm{ml}$ of PBS. Dilutions of the homogenates were made in PBS and plated on to sheep blood $5 \%$ agar. Colonies were counted at $24 \mathrm{~h}$, and the numbers of organisms/ vegetation were calculated. The lower limit of detection of growth by these dilution methods was $<1 \times 10^{2} \mathrm{cfu} /$ vegetation; therefore, each sterile vegetation was assigned a concentration of $9.9 \times 10^{1} \mathrm{cfu} /$ vegetation. All isolates from vegetation and catheter cultures were identified by colonial morphology, amount of $\beta$-haemolysis on sheep blood $5 \%$ agar plates, coagulase testing (BBL) and Gram's staining.

\section{Statistical analysis}

ID50 and confidence intervals were calculated by regression analysis. ${ }^{11}$ Differences among the rates of infection of resected vegetations and catheters were analysed by comparing the ID50 values by use of asymptotic distribution. ${ }^{12}$ An analysis of co-variance comparing the three staphylococcal strains in weights of infected vegetations and the bacterial densities in vegetations was done with inoculum size as the covariate. Fisher's exact test was used to compare the pre-killing mortality rates observed among rats challenged with the three staphylococcal strains.

\section{Results}

Groups of three to five rats were inoculated with each $S$. aureus strain and all three strains were used with each series of animals; $74(89.2 \%)$ of 83 rats were challenged with staphylococci and were deemed evaluable for ID50 studies. Nine animals were excluded because of inappropriate catheter placement, which was documented at the time of killing; three rats each had received the three challenge strains.

The inocula of the three $S$. aureus challenge strains were selected between 3.03 and $4.26 \log _{10}$ doses. Nine inocula were used for the two mutant strains DU5809 and DU5814. Ten inocula were used with the coagulase-expressing parent strain DU5808. The mean number of rats challenged at each inoculum ranged from 2.50 to 2.89 for the three strains. The relatively small number of animals used at each challenge dose accounts for the wide variation observed in bacterial densities in infected vegetations (figure).

The ID50 value of each $S$. aureus strain was obtained for resected vegetations to determine the role of coagulase in the pathogenesis of experimental endocarditis (table). The ID50 (3.59 $\left.\log _{10} \mathrm{cfu} / \mathrm{rat}\right)$ of the coagulase-positive parent strain DU5808 was similar to that of the two coagulase-deficient mutant strains. No significant differences were seen between the ID50 value of the parent strain and those of mutant strains DU5809 $\left(3.50 \log _{10} \mathrm{cfu} / \mathrm{rat}\right)$ or DU5814 $\left(3.72 \log _{10} \mathrm{cfu} / \mathrm{rat}\right)$. The value of $\mathrm{p}=0.08$ is due to the approximate nature of the pairwise procedure. The actual $p$ value should be larger, as suggested by the overlap of the confidence intervals. Qualitative cultures of resected intracardiac catheters mirrored the 


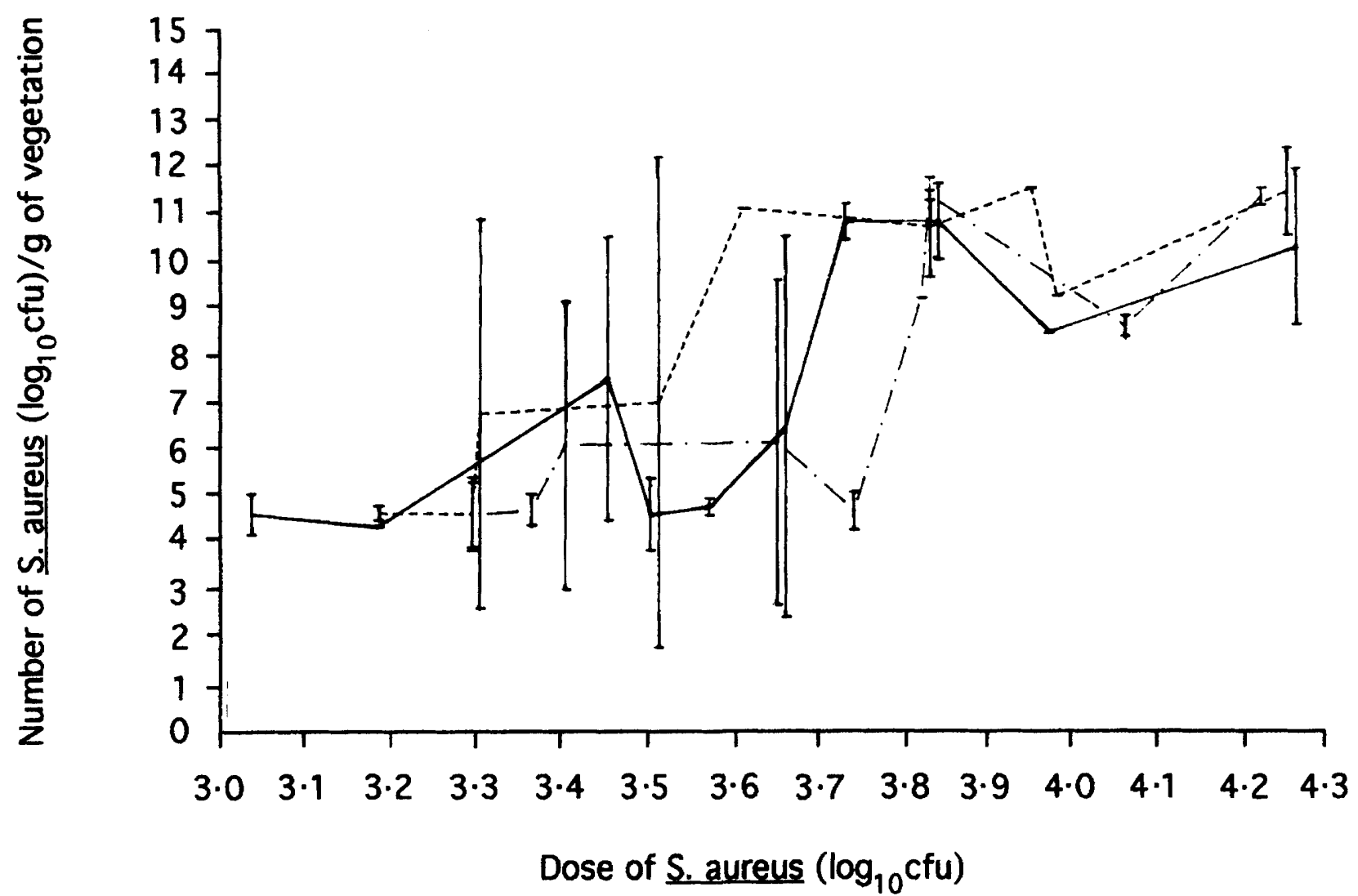

Figure. Quantitative cultures of vegetations from rats challenged with the three $S$. aureus strains. Each value $\left(\log _{10} \mathrm{cfu} / \mathrm{g}\right.$ of vegetation) is shown as mean $(\mathrm{bar}=\mathrm{SEM})$.

Table. ID50 comparisons of infective endocarditis in catheterised rats challenged with the three $S$. aureus strains

\begin{tabular}{|c|c|c|c|c|c|c|c|}
\hline \multirow{2}{*}{$\begin{array}{l}\text { Strain } \\
\text { no. }\end{array}$} & \multirow{2}{*}{$\begin{array}{l}\text { Coagulase } \\
\text { phenotype }\end{array}$} & \multirow{2}{*}{$\begin{array}{l}\text { Number } \\
\text { of rats }\end{array}$} & \multirow{2}{*}{$\begin{array}{c}\text { ID50 } \\
\left(\log _{10} \mathrm{cfu} / \mathrm{rat}\right)\end{array}$} & \multirow{2}{*}{$\begin{array}{l}95 \% \text { Confidence } \\
\text { intervals }\end{array}$} & \multicolumn{3}{|c|}{$\begin{array}{c}\text { Adjusted pairwise } \\
\text { p values }\end{array}$} \\
\hline & & & & & 5808 & 5809 & 5814 \\
\hline DU5808 & Positive & 25 & 3.59 & $(3 \cdot 26,3 \cdot 80)$ & - & 0.90 & 0.55 \\
\hline DU5809 & Deficient & 23 & $3 \cdot 50$ & $(3.32,3.93)$ & - & - & 0.08 \\
\hline DU5814 & Deficient & 26 & $3 \cdot 72$ & $(3.54,3.95)$ & - & - & - \\
\hline
\end{tabular}

cultural analysis of vegetation suspensions; the same animals with infected vegetations contained catheters which were culture-positive. The mean weights of infected vegetations were compared as another measure of virulence. The mean weights of infected vegetations were adjusted by dose and were similar for all three challenge strains $(p=0 \cdot 85)$. The adjusted mean weights in $\mathrm{mg}$ were as follows: DU5808, 32.45 (SEM 5.08), DU5809, 36.12 (SEM 5.27) and DU5814, $32 \cdot 22$ (SEM 5.81).

The results of quantitative cultures of the resected endocardial vegetations are shown in the figure. As the inoculum (dose, $\log _{10} \mathrm{cfu} / \mathrm{rat}$ ) increased, similar increases in the bacterial densities were seen for vegetations excised from rats challenged with the three strains. An analysis of co-variance comparing DU5808, DU5809 and DU5813 adjusted by inoculum size revealed no significant difference in bacterial concentrations in vegetations $(p=0 \cdot 10)$.
Eleven rats with infected vegetations died before killing at $96 \mathrm{~h}$ post-challenge. The pre-killing mortality rates for strains DU5808, DU5809 and DU5814 were $23.1 \%$ (three of 13 ), $50 \%$ (six of 12 ) and $20 \%$ (two of $10)$, respectively. Because of the small sample sizes, the comparison of the mortality rates was made by Fisher's exact test. The rates were not statistically different $(p=0 \cdot 29)$.

\section{Discussion}

The animal model of catheter-induced experimental endocarditis has been used extensively over the last 25 years to examine the pathogenesis of infective endocarditis. ${ }^{13}$ The model is relevant to disease in man and, unlike some other animal models, relatively small inocula can be used to establish infection. Use of an experimental model that employs smaller inocula is important as this should increase the sensitivity of the 
model to distinguish the contribution of one virulence marker of a pathogen in disease production.

Recent work $^{10}$ has shown how a sensitive rat endocarditis model was better able to distinguish the role of a microcapsule in the pathogenesis of infection. Bacteraemia and renal abscess formation resulted from inocula $>10^{6} \mathrm{cfu}$ of staphylococci used to establish disease; neither the type 5 nor the type 8 microcapsule enhanced virulence. ${ }^{14,15}$ When a rat model of experimental endocarditis was employed with the same $S$. aureus strains at much lower inocula, not only was it shown that the microcapsule did not appear to function as a virulence marker, but that it seemed to interfere with other virulence determinants in the production of endocardial infection. While it is possible that other undefined factors accounted for the lack of change in virulence, we believe that the size of the bacterial inocula influenced the virulence of $S$. aureus in each of the different models of infection.

Phonimdaeng et al..$^{7}$ were the first to provide in-vivo data that questioned the assumption that coagulase was a marker of virulence in $S$. aureus. They performed site-specific mutagenesis by recombinational allelereplacement to isolate coagulase-deficient mutants, unlike previous investigators ${ }^{4-6}$ who used chemical mutagenesis to obtain coagulase-negative mutant strains of $S$. aureus. Mice were challenged with parent and mutant strains in models of subcutaneous infection and mastitis. Large inocula $\left(5 \times 10^{7}-\right.$ $2 \times 10^{9} \mathrm{cfu}$ ) were used in both mouse models to establish infection. When compared to the virulence of the coagulase-producing parent strain, the infectivity of the coagulase-negative mutant strains was similar. These data indicated that there was no role for coagulase in the pathogenesis of subcutaneous or intramammary infections. Nevertheless, it was acknowledged that mouse plasma is relatively deficient

\section{References}

1. Waldvogel FA. Staphylococcus aureus (including toxic shock syndrome). In: Mandell GL, Douglas RG, Bennett JE (eds) Principles and practice of infectious diseases, 3rd edn. New York, Churchill Livingstone. 1990: 1489-1510.

2. Foster TJ, O'Reilly M, Bramley AJ. Genetic studies of Staphylococcus aureus virulence factors. In: Wadström T, Eliasson I, Holder I, Ljungh $\AA$ (eds) Pathogenesis of wound and biomaterial-associated infections. London, Springer-Verlag. 1990: 35-46.

3. Mani N, Baddour LM, Offutt DQ, Vijaranakul U, Nadakavukaren MJ, Jayaswal RK. Autolysis-defective mutant of Staphylococcus aureus: pathological considerations, genetic mapping and electron microscopic studies. Infect Immun 1994; 62: 1406-1409.

4. Hasegawa N, San Clemente CL. Virulence and immunity of Staphylococcus aureus BB and certain deficient mutants. Infect Immun 1978; 22: 473-479.

5. Jonsson $\mathbf{P}$, Lindberg $\mathbf{M}$, Haraldsson I, Wadström $\mathrm{T}$. Virulence of Staphylococcus aureus in a mouse mastitis model: studies of alpha hemolysin, coagulase, and protein $\mathrm{A}$ as possible virulence determinants with protoplast fusion and gene cloning. Infect Immun 1985; 49: 765-769.

6. Masuda S. An efficient method for the isolation of a mutant with an extremely low producibility of coagulase from a in coagulase-reactive factor activity ${ }^{16}$ and the suggestion has been made that mammalian hosts with higher levels of coagulase-reactive factor should be chosen for experimental models of infection to evaluate the role of coagulase in virulence. Although the level of coagulase-reactive factor activity of rat plasma has not been measured, the present study provides compelling data that support the non-contributory role of coagulase in the virulence of $S$. aureus.

In addition to being coagulase-deficient, the mutant strain DU5814 was also rendered defective in $\alpha$ and $\beta$-toxin expression by site-directed mutagenesis. ${ }^{8.9}$ Evidence collected in the present investigation suggests that, like the absence of coagulase, the lack of production of $\alpha$ - and $\beta$-toxins by this mutant strain of $S$. aureus did not affect virulence in the rat endocarditis model. Another mutant strain (DU5720) which was derived from strain NCTC 8325-4 and contained a double mutation that resulted in loss of expression of $\alpha$ - and $\beta$-toxins has been used in a mouse mastitis model. ${ }^{9}$ Compared to the parent strain that produced both toxins and to mutant strains that expressed either $\alpha$-toxin (strain DU5719) or $\beta$-toxin (strain DU5725), recovery of the double mutation strain DU5720 from the mouse mammary gland $48 \mathrm{~h}$ post-inoculation with $10^{8} \mathrm{cfu}$ was diminished $(\mathrm{p}<0 \cdot 05)$. Histopathologically, the DU5720 mutant caused less necrosis and allowed greater preservation of cellular architecture of the glands than did the toxigenic strains. Considering the disparate findings between the mouse mastitis model and the rat endocarditis model in regard to the contribution of $\alpha$ - and $\beta$-toxins to virulence, it appears that the role of the toxins may vary depending on the type of animal model employed. In contrast, all observations made to date, regardless of the animal model used, have demonstrated that coagulase does not function as a virulence factor.
Staphylococcus aureus strain. Microbiol Immunol 1983; 27 : 801-805.

7. Phonimdaeng P, O'Reilly M, Nowlan P, Bramley AJ, Foster TJ. The coagulase of Staphylococcus aureus 8325-4. Sequence analysis and virulence of site-specific coagulasedeficient mutants. Mol Microbiol 1990; 4: 393-404.

8. O'Reilly M, de Azavedo JCS, Kennedy S, Foster TJ. Inactivation of the alpha-haemolysin gene of Staphylococcus aureus $8325-4$ by site-directed mutagenesis and studies on the expression of its haemolysins. Microb Pathog 1986; 1 : $125-138$.

9. Bramley AJ, Patel AH, O'Reilly M, Foster R, Foster TJ. Roles of alpha-toxin and beta-toxin in virulence of Staphylococcus aureus for the mouse mammary gland. Infect Immun $1989 ; 57: 2489-2494$.

10. Baddour LM, Lowrance C, Albus A, Lowrance JH, Anderson SK, Lee JC. Staphylococcus aureus microcapsule expression attenuates bacterial virulence in a rat model of experimental endocarditis. J Infect Dis 1992; 165 : 749-753.

11. SAS/STAT User's Guide, Version 6, 4th edn. Cary, NC, SAS Institute. $1990 ; 865-866 ; 1325-1350$.

12. Miller RG. Beyond ANOVA, basics of applied statistics. New York, Wiley. 1986: 246.

13. Baddour LM, Christensen GD, Lowrance JH, Simpson WA. Pathogenesis of experimental endocarditis. Rev Infect Dis $1989 ; 11$ : $452-463$. 
14. Albus A, Arbeit RD, Lee JC. Virulence of Staphylococcus aureus mutants altered in type 5 capsule production. Infect Immun 1991; 59: 1008-1014.

15. Albus A, Liu MJ, Arbeit RD, Lee JC. Virulence studies of transposon-induced mutants of Staphylococcus aureus altered in capsule expression. Abstracts of the 90th Annual
Meeting of the American Society for Microbiol 1990, B-6, p. 27.

16. Jeljaszewicz H, Switalski LM, Adlam C. Staphylocoagulase and clumping factor. In: Easmon CSF, Adlam C (eds) Staphylococci and staphylococcal infections, vol 2. London, Academic Press. 1983: 525-557. 